\title{
Muscular dystrophy with marked Dysferlin deficiency is consistently caused by primary dysferlin gene mutations
}

\author{
Mafalda Cacciottolo ${ }^{1,7}$, Gelsomina Numitone ${ }^{1,7}$, Stefania Aurino ${ }^{1}$, Imma Rosaria Caserta $^{1}$, Marina Fanin ${ }^{2}$, \\ Luisa Politano ${ }^{3}$, Carlo Minetti ${ }^{4}$, Enzo Ricci ${ }^{5}$, Giulio Piluso ${ }^{6}$, Corrado Angelini ${ }^{2}$ and Vincenzo Nigro ${ }^{\star 1,6}$
}

Dysferlin is a 237-kDa transmembrane protein involved in calcium-mediated sarcolemma resealing. Dysferlin gene mutations cause limb-girdle muscular dystrophy (LGMD) 2B, Miyoshi myopathy (MM) and distal myopathy of the anterior tibialis. Considering that a secondary Dysferlin reduction has also been described in other myopathies, our original goal was to identify cases with a Dysferlin deficiency without dysferlin gene mutations. The dysferlin gene is huge, composed of 55 exons that span 233140 bp of genomic DNA. We performed a thorough mutation analysis in 65 LGMD/MM patients with $\leq 20 \%$ Dysferlin. The screening was exhaustive, as we sequenced both genomic DNA and cDNA. When required, we used other methods, including real-time PCR, long PCR and array CGH. In all patients, we were able to recognize the primary involvement of the dysferlin gene. We identified 38 novel mutation types. Some of these, such as a dysferlin gene duplication, could have been missed by conventional screening strategies. Nonsense-mediated mRNA decay was evident in six cases, in three of which both alleles were only detectable in the genomic DNA but not in the mRNA. Among a wide spectrum of novel gene defects, we found the first example of a 'nonstop' mutation causing a dysferlinopathy. This study presents the first direct and conclusive evidence that an amount of Dysferlin $\leq \mathbf{2 0} \%$ is pathogenic and always caused by primary dysferlin gene mutations. This demonstrates the high specificity of a marked reduction of Dysferlin on western blot and the value of a comprehensive molecular approach for LGMD2B/MM diagnosis.

European Journal of Human Genetics (2011) 19, 974-980; doi:10.1038/ejhg.2011.70; published online 27 April 2011

Keywords: dysferlin; limb-girdle muscular dystrophy; Miyoshi myopathy; nonsense-mediated mRNA decay; comparative genomic hybridization

\section{INTRODUCTION}

Mutations in the dysferlin gene are responsible for three main dystrophic phenotypes: limb-girdle muscular dystrophy type $2 \mathrm{~B}$ (LGMD2B; MIM\# 253601 1,2 ), Miyoshi myopathy (MM; MIM\# $254130^{2}$ ) and distal myopathy with anterior tibialis onset (DMAT; MIM\# $606768 .^{3}$ ). During the course of the disease, the phenotypes show a substantial amount of overlap with weakness extending from the proximal to distal muscles and vice versa. ${ }^{4,5}$ Even if clinical differences are reported, they may not be so striking at the pathological level. ${ }^{6} \mathrm{~A}$ unique finding within the spectrum of muscular dystrophies is that the majority of Dysferlin-deficient patients appear to have no initial muscle weakness. Indeed, they often show a good performance at sport or have jobs that require physical activity, suggesting that exercise may be a disease-triggering factor. ${ }^{7,8}$ A secondary Dysferlin reduction has also been observed in calpain-3 (LGMD2A ${ }^{9}$ ) and caveolin-3 $\left(\right.$ LGMD1C $\left.{ }^{10}\right)$. A similar phenotype has also been described in patients with anoctamin-5 gene (LGMD2L ${ }^{11}$ ) mutations.

The dysferlin gene is huge and routine mutation detection is a long and expensive process. In addition, there are no prevalent mutations, but, instead, 415 different allelic variants have been identified thus far (http://www.dmd.nl). The cost-effectiveness of a dysferlin gene mutation screening using DHPLC approaches has been reported in large groups of patients with the identification of many mutations, therefore validating the efficacy of genomic mutational screening for routine diagnosis. ${ }^{12}$

Most authors have been able to identify the majority of dysferlin gene mutations (but not all) when Dysferlin was absent from the muscle. ${ }^{13,14}$ Several mutational screenings have been reported, many of them based on isolated cases/families and the identification of private mutations. ${ }^{15-22}$ The biggest cohort was analysed by Krahn et al, ${ }^{12}$ composed of 134 patients, including a group that had previously been described. ${ }^{18}$ The authors identified at least one pathological allele in 119/134 patients $(88 \%)$. The success rate was higher than that in other LGMD cases, ${ }^{23}$ but not all cases were solved, indicating either that other genes causing secondary defects of Dysferlin are rarer, or that the mutation analyses have been inaccurate in that they have missed some of the defects.

Our original aim was to focus on LGMD cases with a marked Dysferlin reduction and no mutation. To achieve this objective, we

${ }^{1}$ TIGEM (Telethon Institute of Genetics and Medicine), Napoli, Italy; ${ }^{2}$ Department of Neurosciences, University of Padua, Padova, Italy; ${ }^{3}$ CIRM and Cardiomyology and Genetics Section, Dipartimento di Medicina Sperimentale, Seconda Università degli Studi di Napoli, Napoli, Italy; ${ }^{4}$ Muscular and Neurodegenerative Disease Unit, G. Gaslini Institute, University of Genoa, Genova, Italy; ${ }^{5}$ Department of Neurosciences, Università Cattolica Policlinico A. Gemelli, Rome, Italy; ${ }^{6} \mathrm{CIRM}$ and Dipartimento di Patologia Generale, Seconda Università degli Studi di Napoli, Napoli, Italy

*Correspondence: Professor V Nigro, Dipartimento di Patologia Generale, Telethon Institute of Genetics and Medicine (TIGEM), Seconda Università degli Studi di Napoli, S. Andrea delle Dame, via L. De Crecchio 7, Napoli 80138, Italy. Tel: +39 081566 5704; Fax: +39 081566 5704; E-mail: vincenzo.nigro@unina2.it or nigro@tigem.it ${ }^{7}$ These authors contributed equally to this work.

Received 8 November 2010; revised 15 February 2011; accepted 16 February 2011; published online 27 April 2011 
performed a complete mutation analysis of the dysferlin gene in a group of $65 \mathrm{LGMD} / \mathrm{MM}$ patients with a marked reduction or absence of the protein detected by western blot. We used all available screening methods starting from genomic DNA and mRNA. Here we show the high specificity of the absence or marked reduction of dysferlin expression on muscle biopsy and the high specificity and sensitivity of a comprehensive molecular approach in the diagnosis of LGMD2B/MM.

\section{PATIENTS AND METHODS}

\section{Patient recruitment}

The patients were between 26 and 77 years of age. They had serum levels of creatine kinase between 1200 and $8000 \mathrm{U} / \mathrm{L}$ (with an average value of $3507 \mathrm{U} / \mathrm{L})$. These patients showed an absence or marked reduction $(5-20 \%$ of the normal amount) of Dysferlin in their skeletal muscle. A total of 10 out of 65 were affected by Miyoshi myopathy, whereas the remaining 55 had an LGMD2B phenotype. In our study we analysed eight pairs of siblings. Only three of these patients are wheelchair-confined in accordance with the slow progression rate of the dysferlinopathies. In particular, the age at which they began to use a wheelchair was very variable $(22,39$ and 49 years of age, respectively), again in accordance with the phenotypical variability of the dysferlinopathies. ${ }^{5,24,25}$

Biological samples were obtained from 65 patients (61 of whom were Italians) from different centres: Naples (16/65), Rome (5/65), Genoa (8/65), Padua (31/65), Ankara (Turkey; 3/65) and Buenos Aires (Argentina; 1/65). For all these patients genomic DNA and/or mRNA from blood samples or muscle biopsies were available.

\section{Muscle biopsy}

At the time of diagnosis, an open biopsy from the quadriceps femoris muscle was obtained under local anaesthesia after written informed consent.

Muscle biopsy specimens were frozen in isopentane, cooled in liquid nitrogen and stored at $-80^{\circ} \mathrm{C}$ until processed.

\section{Multiple western blot analysis of muscle proteins and quantification}

Western blot (WB) analysis and detailed protein analyses were performed as previously described, ${ }^{26}$ using a mixture of monoclonal antibodies against Calpain-3 (Calp12A2, diluted 1:800), $\alpha$-Sarcoglycan (diluted 1:300), $\beta$-Sarcoglycan (diluted 1:300), Dystrophin (Dys-2, diluted 1:1000) and Dysferlin (Hamlet, diluted 1:1000), all purchased from Novocastra (Newcastle, UK). In brief, the quantity of muscle proteins in the samples from the controls and patients was determined by densitometry using ImageJ software v.1.34n (Image Software Services, Shirley, MA, USA) and normalized to the amount of tissue loaded in each lane, using the skeletal myosin bands in the post-transfer Coomassie blue-stained gels. The values in each patient were expressed as percentages of the mean of the controls.

\section{PCR conditions from gDNA}

The dysferlin gene (NM_001130987.1, 55 coding exons) was amplified by PCR from genomic DNA. All the exons and flanking intron sequences were amplified using specific primer pairs (Supplementary Table S1). In a final volume of $25 \mu \mathrm{l}, 60-75 \mathrm{ng}$ of genomic DNA was combined with $0.6 \mu \mathrm{m}$ of each primer, $0.6 \mathrm{mM}$ all dNTPs, buffer LB1X $(20 \mathrm{~mm}$ Tris, $10 \mathrm{~mm}$ Hepes, $2.5 \mathrm{~mm}$ magnesium sulfate, $10 \mathrm{~mm}$ potassium chloride and $10 \mathrm{~mm}$ ammonium sulfate) or buffer LC1X (20 mm Tris, $10 \mathrm{~mm}$ Hepes, $2.5 \mathrm{~mm}$ magnesium sulfate, $20 \mathrm{~mm}$ ammonium sulfate and 5\% glycerol) and $0.9 \mathrm{U}$ of AmpliTaq-Gold (Applied Biosystems for Life Technologies, Monza, Italy). After polymerase activation for $10 \mathrm{~min}$ at $95^{\circ} \mathrm{C}$, reactions were carried out for $30 \mathrm{~s}$ at $95^{\circ} \mathrm{C}, 1 \mathrm{~min}$ at $\mathrm{Tm}$ (see Supplementary Table S1) and $1 \mathrm{~min}$ at $68^{\circ} \mathrm{C}$, for 30 cycles.

\section{DHPLC analysis}

We performed comparative mutation scanning to select amplicons for aberrant DHPLC profiles not shared by the normal controls. DHPLC analysis was performed on a WAVE DNA fragment analysis system (Transgenomic Inc., San Jose, CA, USA) equipped with a DNASep column (3500 High Throughput (HT)) using a UV-C scanner to detect eluted DNA. ${ }^{27}$

\section{mRNA extraction and cDNA preparation}

We used a TRIzol reagent (Invitrogen, Carlsbad, CA, USA) according to the manufacturer's instructions to extract RNA from the muscle biopsies and the PAXgene Blood RNA Kit (Qiagen, Hilden, Germany) to extract RNA from the blood ${ }^{28}$

The retrotranscription reaction was performed using $2 \mu \mathrm{g}$ of total mRNA, according to the procedure described in the SuperScript III kit (Invitrogen).

\section{RT-PCR and long PCR}

We amplified the dysferlin cDNA in 13 overlapping fragments (Supplementary Table S2). The reaction was performed in a final volume of $25 \mu \mathrm{l}$ using $1 \mu \mathrm{l}$ of cDNA, $1 \mu \mathrm{m}$ of each primer, $2 \mathrm{mM}$ of dNTPs, Buffer JD1X, ${ }^{29} 0.5 \mathrm{U}$ of LA-Taq DNA polymerase (Takara BIO Inc.) and 1 UI of Pfu polymerase (Stratagene, Milan, Italy). Thermocycling was then carried out for $30 \mathrm{~s}$ at $94{ }^{\circ} \mathrm{C}, 1.30 \mathrm{~min}$ at $\mathrm{Tm}$ (see Supplementary Table S2) and $2 \mathrm{~min}$ at $68^{\circ} \mathrm{C}$, for 30 cycles.

Fragments were recovered from agarose gels by using the Mini Elute Gel Extraction Kit (Qiagen) and then sequenced.

\section{Sequencing}

BigDye Terminator sequencing chemistry and ABI3130XL automatic DNA sequencer (Applied Biosystems, Foster City, CA, USA) were used. Each nucleotide change was verified by reverse sequencing and, in addition, by the sequencing of an overlapping PCR product obtained with different primers. Mutations were numbered on the basis of protein (GenBank NP_003485) and cDNA sequence (GenBank NM_003494). Nucleotides were numbered according to international recommendations. ${ }^{30-32}$

\section{Array comparative genomic hybridization (CGH)}

A custom array CGH (MotorChip 2.0) was developed using the Agilent $8 \times 60 \mathrm{~K}$ (Agilent Technologies Italia S.p.A., Milan, Italy) format (SurePrint G3 arrays). All dysferlin exons, both the $5^{\prime}$ - and $3^{\prime}$-UTR, 2000 bp at the $5^{\prime}$ end of the gene (covering the dysferlin promoter) were included. Probes were designed based on the exon and flanking intron sequences. Array CGH results were confirmed by independent assays, such as real-time PCR, long PCR and MLPA.

\section{Bioinformatic software}

Splice View software was useful to verify the effect of intronic variants on mRNA splicing (http://bioinfo.itb.cnr.it/oriel/splice-view.html). Conservation analysis was performed using ClustalW2 (http://www.ebi.ac.uk/Tools/clustalw2/ index.html). To assess intronic and exonic mutations leading to splicing defects, the Human Splicing Finder website (http://www.umd.be/SSF/) was consulted. ${ }^{33}$

\section{RESULTS}

To select patients with a Dysferlin deficiency from a heterogeneous population of patients affected with an unclassified form of LGMD or $\mathrm{MM}$, we previously analysed muscle samples by a multiple WB. A group of 65 patients who showed a marked reduction or absence of Dysferlin were included in the study (Figures $1 \mathrm{a}$ and $\mathrm{b}$ ). We excluded cases having more than 20\% Dysferlin, using a quantitative WB assay. ${ }^{26}$ The average Dysferlin level was $5 \% \pm 5$. We combined different screening methods to identify the causative alleles (Figure 1c).

\section{From genomic DNA-DHPLC}

Despite the incomplete DHPLC sensitivity and the noise of the variants and polymorphisms, this first step was chosen for its cost-effectiveness. ${ }^{34}$ We screened by DHPLC and targeted a sequencing of all the 55 exons and flanking introns from the genomic DNA. DHPLC analysis was performed on a first group of 52 patients. We identified 47 causative mutations, 28 of which were new (Supplementary Table S3). A full molecular diagnosis (both alleles) was provided for 35 out of 52 patients (67\%).

\section{mRNA analysis}

We next performed mRNA analysis in cases without mutations or with ambiguities (one allele, new mutations, possible splice defects 

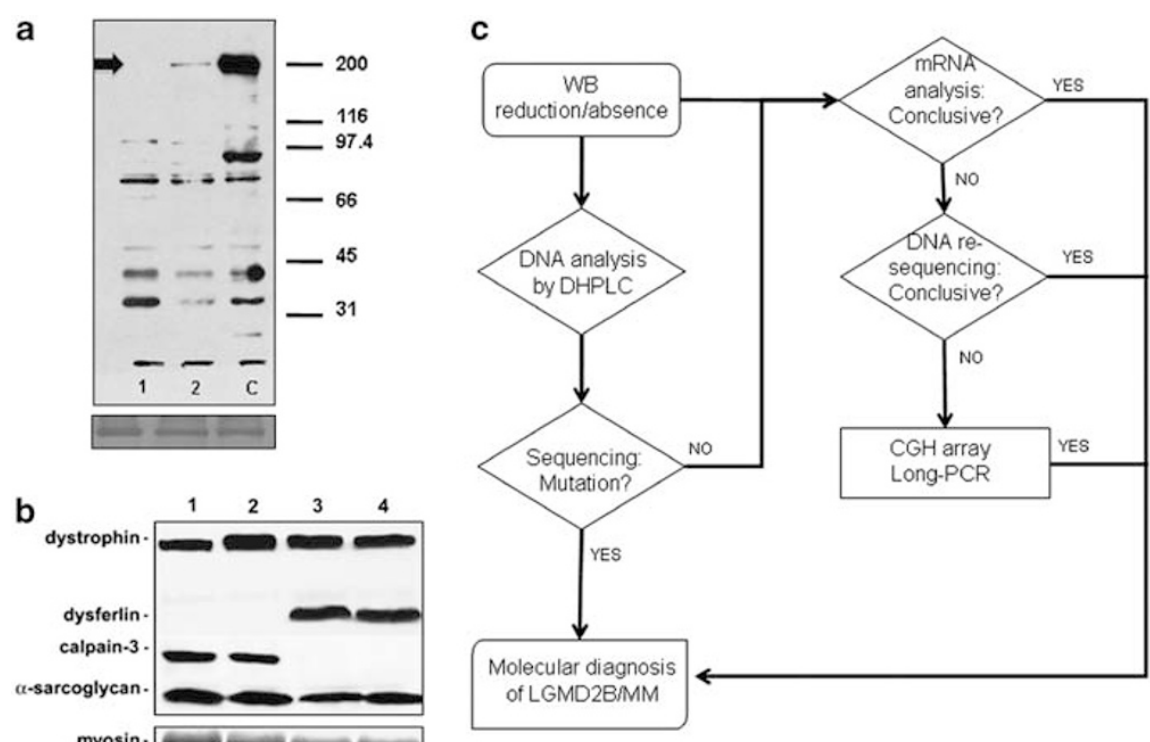

Figure 1 Mutational scanning. (a) The picture shows the western blot on muscle lysate from patients (1 and 2) and control (c). As observed, patient 1 showed a complete absence of the dysferlin-specific band, whereas sample 2 shows a residual expression (5\%) of dysferlin protein compared with the control (as indicated by the arrow). (b) An exemplary image of a multiple western blot assay used in this study to screen and select the patients for further molecular analyses (samples 1 and 2 show a complete dysferlin deficiency). For both $\mathbf{a}$ and $\mathbf{b}$, the skeletal myosin bands in the post-transfer Coomassie blue staining gels were used to normalize the amount of loaded protein. (c). The flow chart shows the general design of the mutation analysis.

and so on). We first confirmed the splice mutations on cDNA. We also extended the analysis to an additional group of 13 patients.

Two sources of mRNA were considered: (1) skeletal muscle that, when available, is the first choice for the expression level and canonical splicing of muscle dysferlin; (2) leukocytes that are easy to collect and representative of non-muscle dysferlin, with some differences in the alternative splicing of exons $5 \mathrm{a}, 17$ or $40 \mathrm{a} .{ }^{35,36}$ For this analysis, we performed 16 muscle biopsies and, when not possible, collected blood samples. The cDNA was amplified by PCR in 13 overlapping fragments and then sequenced (Supplementary Figure S1). We identified 15 mutations, eight of which were novel. mRNA analysis was useful to demonstrate the effect of two intronic variations on RNA splicing (Figures $2 \mathrm{a}$ and $\mathrm{b}$ ). Patient X311 carrying the homozygous mutation $906+4 A>G$ showed a smaller amplification product of fragment 3 (including approximately exons 7-12) of the dysferlin cDNA compared with the control (Figure 2a). Direct sequencing showed that exon 9 was skipped (Figure 2a). At the protein level, exon 9 skipping causes the loss of a part of the C2B domain, important for the protein function. Therefore, this variation should be considered as pathological.

The transversion 1639-6T $>$ A, found in a homozygosity state in patient X389, inactivated the donor splice site (with the reactivation of a new donor site in intron 18) resulting in retention of $4 \mathrm{bp}$ from intron 18 sequence (Figure 2b) and a frameshift (Supplementary Table S3).

Patient X546 (classified as having severe LGMD2B) showed $<5 \%$ Dysferlin. Molecular analysis confirmed the presence of a frameshift mutation, 1-bp deletion (g.2077delC) on exon 22 (Figure 2c) and the heterozygous deletion of the entire exon 17 (Figure 2d). Exon 17 skipping did not affect the open reading frame, but the amino acid at the exon junction changed (GAG > GTG, g.1481_1522del, p.E494V+ex17skipping). The alternative splicing of the exon 17 had previously been identified and characterized as blood cell isoform, ${ }^{36}$ but it had never been detected in the muscle.

\section{DNA resequencing}

All exon and flanking intron resequencing was used to confirm all the mutations. We identified three additional mutations, the diagnosis being completed in 58/65 patients (Table 1). Surprisingly, six apparently homozygous alleles were not confirmed by the DNA analysis. These alleles were heterozygous, and for three out of six patients a second nonsense mutation was identified in other regions of the gene. This can be explained by the nonsense-mediated decay (NMD) of the mRNA. ${ }^{16}$ (Figure 2e). For the other three patients with NMD, the promoter region was not mutated. ${ }^{37}$

\section{Array CGH, real-time PCR and long PCR}

In all cases with an incomplete gene testing ( 0 or 1 mutated allele), we performed a CGH array to identify possible heterozygous intragenic rearrangements, such as deletions or duplications ${ }^{38}$ (Table 1). We used a minimum of three probes per exon plus promoter probes covering a genomic region of $220 \mathrm{~kb}$ using a total of 196 probes. We identified a heterozygous duplication involving the $5^{\prime}$ end of the gene from exon 1 to 22 (3484), and a heterozygous deletion (X583). In addition, we performed a long PCR on the mRNA and/or gDNA using primers located at distant positions in the transcript in order to confirm the alterations.

\section{Mutation spectrum}

The exhaustive molecular analysis of the dysferlin gene led to the identification of 65 different mutations, 38 of which (60\%) had not previously been described (Supplementary Table S3 and Figure 3). Thirty-one patients showed homozygous alleles (47.7\%), most confirmed by segregation studies. Mutation scanning methods used in our study led to the identification of 19 additional novel non-pathological variants (Supplementary Table S4). The present study confirmed the absence of a mutational hot-spot region as well as the spreading of mutations along the entire gene. We detected 9 (14\%) nonsense mutations, 28 (43\%) missense mutations, 5 (8\%) splicing mutations, 
a

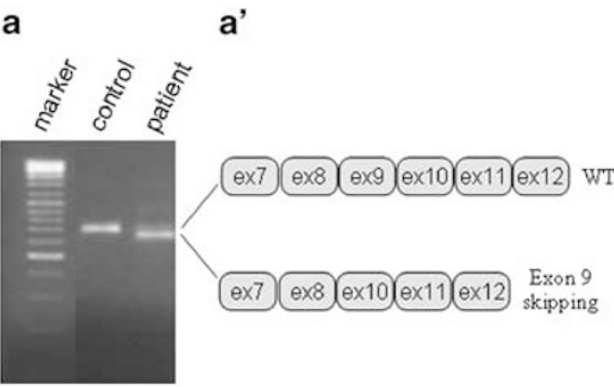

C

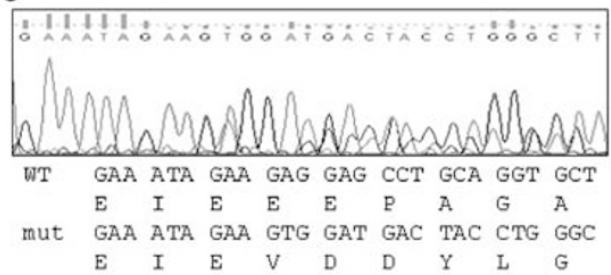

d

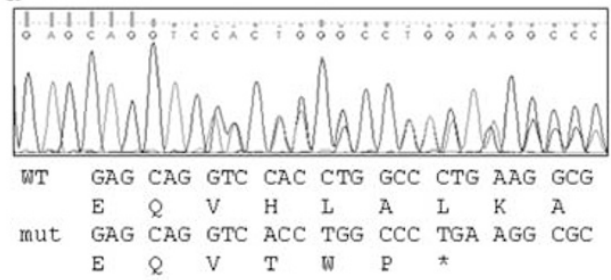

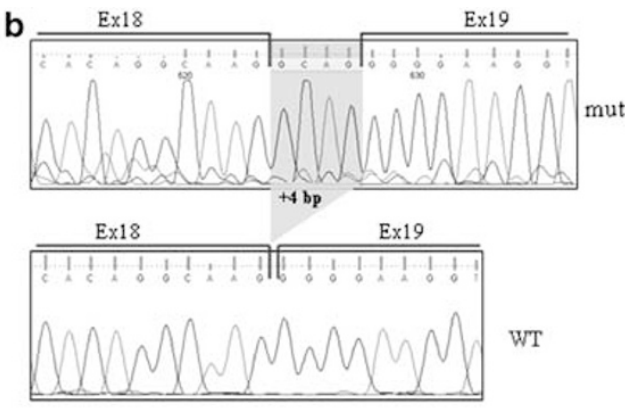

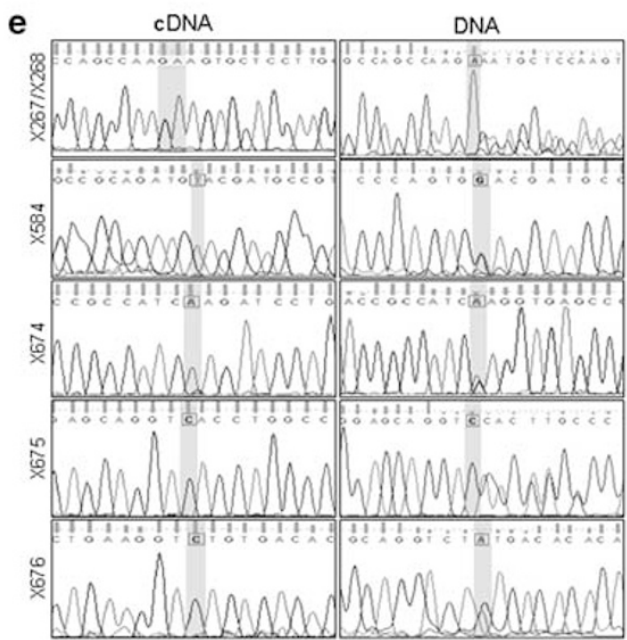

Figure 2 Elusive/peculiar mutations. (a) Exon 9 skipping in a patient with the variation $906+4 \mathrm{~A}>\mathrm{G}$ in homozygous state. RT-PCR products between DYSF exons 7 and 12 showing the aberrantly spliced transcript. (a') Graphical presentation of the sequence composition of the wild-type transcript and the aberrantly spliced transcript with the exon 9 skipping. (b) Partial intron 18 retention in a patient with the variation 1639-6T>A in homozygous state. RT-PCR product sequencing between DYSF exons 12 and 19 showing a 4-bp retention of the intron 18, which is predicted to result in a truncated protein. (c and d) Analysis of the cDNA sequence of patient X546 for (c) fragment 5 (including exon 22) and (d) fragment 4 (including exon 17). Both mutations produce a frameshift. (e) Sequence analysis performed on specific fragments of dysferlin obtained from cDNA and DNA. The same mutation is shown for both cDNA and DNA. The mutated nucleotide is highlighted in blue. All the patients showed the mutation in homozygous state on cDNA and heterozygous state on DNA. The color reproduction of this figure is available on the html full text version of the manuscript.

Table 1 Number of causative alleles identified by the different techniques

\begin{tabular}{lcccc}
\hline Mutations & mRNA & $\begin{array}{c}\text { gDNA } \\
\text { DHPLC DNA }\end{array}$ & $\begin{array}{c}\text { Array CGH } \\
\text { sequencing }\end{array}$ & $\begin{array}{l}\text { sequencing } \\
\text { real-time/long PCR }\end{array}$ \\
\hline Oalleles & 5 & 0 & 0 & 0 \\
1 allele & 12 & 8 & 5 & 5 \\
2 alleles & 35 & 18 & 4 & 0 \\
Samples examined & 52 & 26 & 9 & 5 \\
\hline
\end{tabular}

$20(30.5 \%)$ frame-shift mutations, $1(1.5 \%)$ non-stop mutation and $2(3 \%)$ large genomic rearrangements (Table 2).

For the novel mutations, their absence was demonstrated in $>1000$ control chromosomes from healthy individuals of matched ethnic origin. In all 10 patients with $10-20 \%$ of Dysferlin, we always found at least one missense mutation (100\%), whereas among 24 patients with $0 \%$ Dysferlin a missense mutation was only found in 7 cases $(29 \%)$.

\section{DISCUSSION}

The present study demonstrates that the marked reduction of Dysferlin observed in LGMD/MM patients is not genetically heterogeneous. Given the location of Dysferlin, close to the muscle membrane, its interactions with other proteins, and cumulative data about the existence of secondary dysferlinopathies, this is surprising, because in other membrane complexes, such as sarcoglycans, a marked secondary reduction of each component is common. A Dysferlin reduction has been observed in primary calpain-3 deficiency $\left(\right.$ LGMD2A ${ }^{9}$ ) or Caveolin-3 deficiency $\left(\right.$ LGMD1C $\left.^{10}\right)$. An LGMD/MM phenotype has also been observed in patients carrying mutations in the Anoctamin-5 gene (LGMD2L $\left.{ }^{11}\right)$.

Our results derive from an exhaustive analysis of RNA and DNA from 65 patients having a severe Dysferlin reduction. In theory, it has been claimed that a DNA analysis is necessary to diagnose a primary dysferlinopathy. ${ }^{39}$ In practice, however, it is not easy. The dysferlin gene is huge and composed of 55 exons. It spans $233140 \mathrm{bp}$ of genomic DNA and generates a 6.9-kb-wide transcript. In our mutation-screening flowchart (Figure 1), the DNA analysis was first carried out by a DHPLC of all exons and flanking introns. DHPLC is cheaper, but it can produce false-negative/positive results and therefore it can only have a screening value. ${ }^{40}$ A second problem with DHPLC is with regard to the huge number of polymorphisms and variants that are present in this gene (Supplementary Table S4). These are located in all exons and confound an interpretation of the results with many heteroduplex shifts per patient. We therefore used a second technique based on the sequence analysis of the dysferlin cDNA. When a muscle 


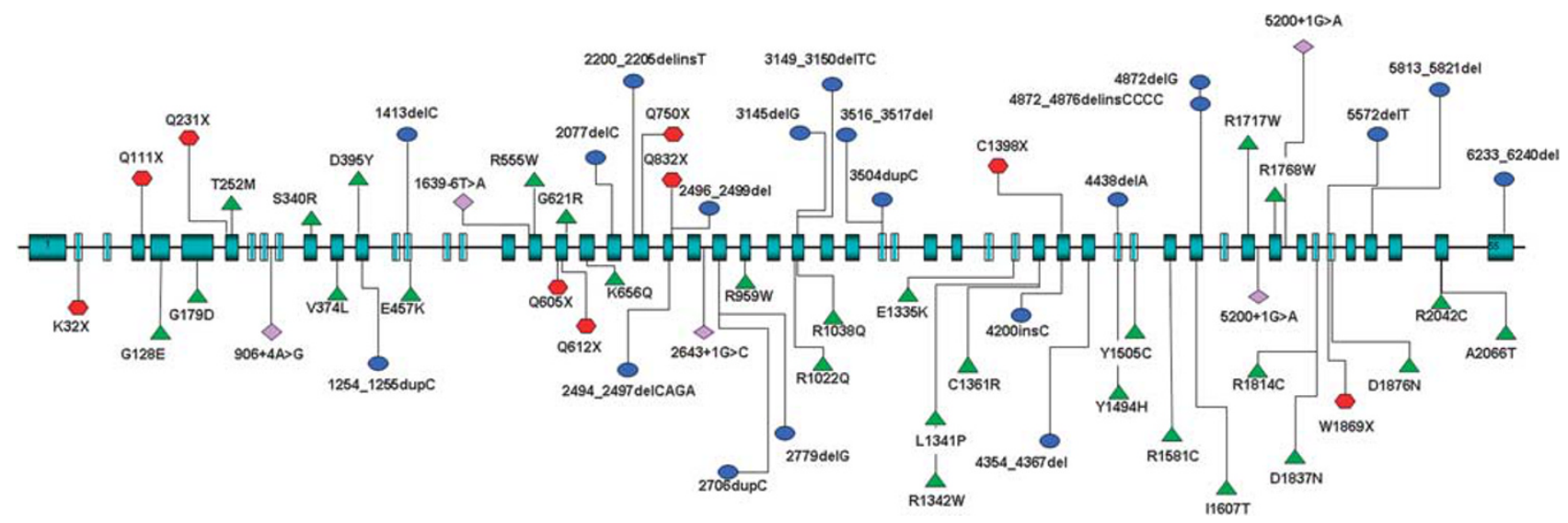

Figure 3 Mutation spectrum. The picture shows the position of all the mutations identified in this study. $\Delta$ identifies missense mutations; $\bigcirc$ identifies the frameshift (del/ins) mutation; $\diamond$ identifies the mutations affecting the splicing mechanism; $\bigcirc$ identifies the nonsense mutation.

Table 2 Classification of all mutation types identified (Het: heterozygote, Hom: homozygote)

\begin{tabular}{lcrr}
\hline & & \multicolumn{2}{c}{ Status } \\
Class of mutation & Mutations (\%) & Het & Hom \\
\hline Missense & $28(43 \%)$ & 27 & 12 \\
Nonsense & $9(14 \%)$ & 9 & 5 \\
Splice site & $5(8 \%)$ & 2 & 5 \\
Frameshift & $20(30.5 \%)$ & 24 & 8 \\
Non-stop & $1(1.5 \%)$ & 0 & 1 \\
Genomic rearrangements & $2(3 \%)$ & 2 & 0
\end{tabular}

Numbers indicate how many mutation types were discovered.

biopsy was not available, we were able to analyse the patients' mRNA from blood, as Dysferlin is highly expressed in the monocytes. This method $^{28,35}$ is less invasive and can provide an adequate amount of mRNA: the analysis helped us to understand the pathogenic role of the two intronic variants identified by DNA analysis, both leading to an alteration of the splicing mechanism (Figures $2 \mathrm{a}$ and $\mathrm{b}$ ).

Despite the larger number of cases identified by mRNA analysis, this method alone can be faulty when the mutated allele is not expressed. We showed that the mechanism of nonsense-mediated $m R N A$ decay (NMD) also occurred in dysferlinopathy. ${ }^{16}$ In six out of 65 patients (Figure 2d) we identified a homozygous mutation in cDNA, a mutation that was heterozygous in gDNA. By direct sequencing of gDNA, we identified in $3 / 6$ patients (X584, X674, $\mathrm{X} 676)$ an additional frameshift mutation that was missed by DHPLC. For the three other patients (X267, X268, X675), we failed to identify the primary cause of the missing mRNA expression of the second allele; however, the NMD confirmed the primary involvement of the dysferlin gene.

This confirms that mRNA analysis alone can be faulty, as true homozygote patients cannot be distinguished from compound heterozygote patients with important consequences in respect of genetic counselling.

Third, we resequenced all the relevant genomic regions, and three additional mutations were found. Furthermore, we used three additional methods: long PCR, real-time PCR and array CGH.

Particularly noteworthy was the first evidence of a non-stop mutation as a new pathological mechanism involved in the dysferlinopathies. Patient X295 carries a homozygous 8-bp (g.6233_6240del, p. P2078fsNON STOP) deletion that was identified in exon 55 of the dysferlin gene. The deletion led to a frameshift in the reading frame with the loss of the stop codon (Figures $4 \mathrm{a}$ and $\mathrm{b}$ ). We supposed that the new reading frame could give rise to the translation of 97 additional amino acids through the $3^{\prime}$ end of the mRNA. The patient showed a residual expression of $<10 \%$ of larger-sized Dysferlin in the skeletal muscle (Figure 4c). We hypothesize that the mutation could cause a mechanism of non-stop mRNA decay. Indeed, it was demonstrated that in the eukaryotes there is a mechanism of degradation of mRNA lacking the stop codon. ${ }^{4-44}$ Non-stop mutation has previously been identified in the ACTAl gene. ${ }^{45}$

Many groups have questioned the value of protein analysis in carrying out a correct diagnosis. Fanin et al ${ }^{26}$ observed that the levels of Dysferlin were reduced to $50 \%$ of those of the controls in the carriers of LGMD2B. They showed that a reduction of $50 \%$ indicated both familial and isolated LGMD2B heterozygotes, and suggested the use of Dysferlin protein testing to select muscle biopsies from suspected carriers for a subsequent mutation analysis. ${ }^{26}$

Our data support the dysferlin gene as the unique cause of Dysferlin deficiency between 0 and $20 \%$ by WB analysis. Although for three patients $(3484,4132$ and X147) the second allele was not identified, this was only because of incomplete testing for insufficient DNA. However, this does not affect the main conclusions of the study, because these patients show sure causative alleles (frameshift/ duplication) that cannot be coincidental.

This marked reduction is necessary to affect muscle membrane repair. We cannot exclude the presence of other functional mutations, but a direct proof of pathogenicity is always required, as the dysferlin gene shows a large number of variants and polymorphisms that can be misleading. In these cases, the possible lack of mutations in the dysferlin gene may be because of incomplete genetic testing.

The results obtained in this present paper have an immediate diagnostic application: a Dysferlin reduction to $20 \%$ (which can also be measured from blood monocytes ${ }^{28,35}$ ) can be used to identify LGMD2B with $100 \%$ accuracy. In the case of LGMD2B this observation is noteworthy. When a rapid Dysferlin blood testing will be available, important decisions will derive, such as to avoid steroids (that are ineffective/deleterious in LGMD2B in contrast with other forms of muscular dystrophy) and any distressing sport in children.,46

Although it is generally agreed that an extensive molecular analysis has a high cost, a precise determination of the dysferlin gene is, however, particularly important from a diagnostic/counselling 


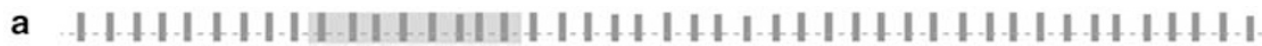
CTGGTGAAGCCCTTCAGCTGAGGACTCTCCTGCCCTGTAGAAGGG

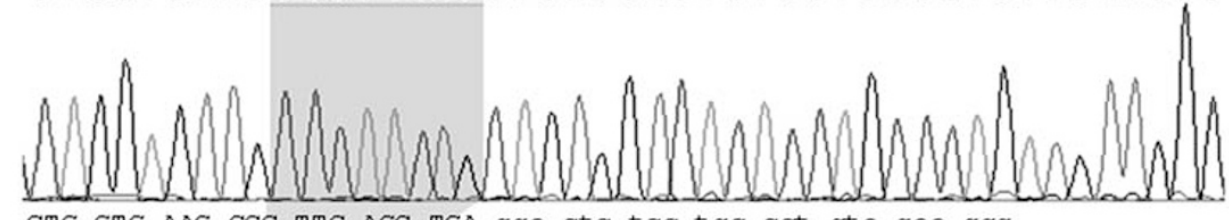

CTG GTG A.AG CCC TTC AGC TGA gga ctc tCC tge cet gta gaa ggg

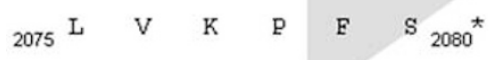

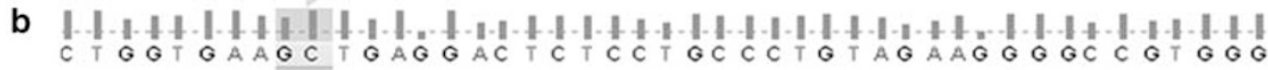
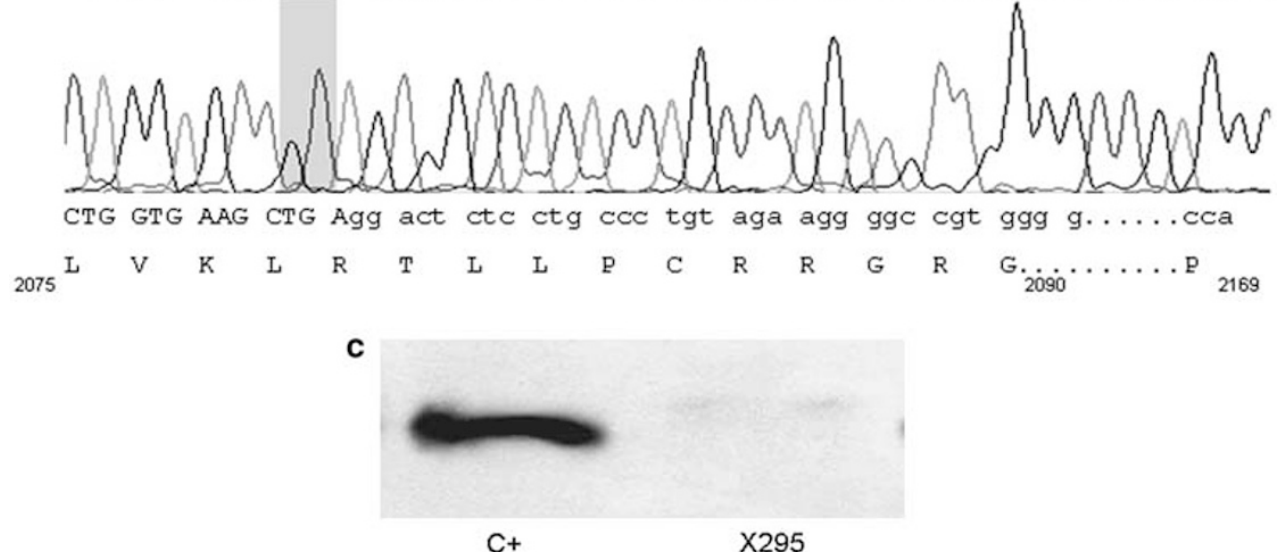

Figure 4 Non-stop mutation. (a and $\mathbf{b}$ ) Analysis of DNA sequence obtained from a control (a) and a patient (b). The mutated base is highlighted in blue. The sequence of exon 55 shows a homozygous deletion of $8 \mathrm{bp}$ (g. 6233_6240del; p. Pro2078LeufsNON STOP). The frameshift skips the stop codon and produces hypothetically the translation of 97 additional amino acids. Both nucleotide and translated sequences are reported for both samples. (c) The picture shows the western blot on muscle lysate from a patient (X295) and control (c). As observed, patient X295 showed a residual expression (<10\%) of larger sized Dysferlin, compared with the control. The color reproduction of this figure is available on the html full text version of the manuscript.

perspective and in view of the development of a future therapeutic strategy. A successful recognition of all the mutations demonstrates the power of a combined diagnostic strategy. More importantly, a complete genetic testing should be applied to all other LGMD cases. ${ }^{47}$

\section{CONFLICT OF INTEREST}

The authors declare no conflict of interest.

\section{ACKNOWLEDGEMENTS}

This study was supported by grants from Telethon, Italy (TIGEM-TNP42TELC and GTB07001), from FP7/2007-2013 under grant agreement no. 223143 (project acronym: TECHGENE), and from Ministero della Salute (Ricerca Finalizzata RF-MUL-2007-666195). We thank Aon Benfield Italia S.p.A.-Milan for the generous gift of a Robot. We acknowledge the Neuromuscular Bank of Tissues and DNA samples (NMTB) for collecting samples (CA and MF), the EUROBIOBANK supported by TREAT-NMD, Manuela Dionisi and the Telethon Facility of Mutation Detection for DHPLC analyses and Anna Cuomo and Laura Mondrone for sequencing.

1 Bashir R, Britton S, Strachan T et al: A gene related to Caenorhabditis elegans spermatogenesis factor fer- 1 is mutated in limb-girdle muscular dystrophy type 2B. Nat Genet 1998; 20: 37-42.

2 Liu J, Aoki M, Illa I et al: Dysferlin, a novel skeletal muscle gene, is mutated in Miyoshi myopathy and limb girdle muscular dystrophy. Nat Genet 1998; 20: 31-36.
3 IIla I, Serrano-Munuera C, Gallardo E et al: Distal anterior compartment myopathy: a dysferlin mutation causing a new muscular dystrophy phenotype. Ann Neurol 2001; 49: $130-134$.

4 Nguyen K, Bassez G, Krahn M et al: Phenotypic study in 40 patients with dysferlin gene mutations: high frequency of atypical phenotypes. Arch Neurol 2007; 64: $1176-1182$.

5 Ueyama $\mathrm{H}$, Kumamoto $\mathrm{T}$, Horinouchi $\mathrm{H}$ et al: Clinical heterogeneity in dysferlinopathy. Intern Med 2002; 41: 532-536.

6 Paradas C, Llauger J, Diaz-Manera J et al: Redefining dysferlinopathy phenotypes based on clinical findings and muscle imaging studies. Neurology 2010; 75: 316-323.

7 Borsato CPR, Fanin M, Pegoraro E et al: Relation between LGMB2B progression and physical activity. Neuromuscul Disord 2007; 17: 1.

8 Klinge L, Aboumousa A, Eagle $M$ et al: New aspects on patients affected by dysferlin deficient muscular dystrophy. J Neurol Neurosurg Psychiatry 2010; 81: 946-953.

9 Anderson LV, Harrison RM, Pogue R et al: Secondary reduction in calpain-3 expression in patients with limb girdle muscular dystrophy type 2B and Miyoshi myopathy (primary dysferlinopathies). Neuromuscul Disord 2000; 10: 553-559.

10 Matsuda C, Hayashi YK, Ogawa M et al: The sarcolemmal proteins dysferlin and caveolin-3 interact in skeletal muscle. Hum Mol Genet 2001; 10: 1761-1766.

11 Bolduc V, Marlow G, Boycott KM et al: Recessive mutations in the putative calciumactivated chloride channel Anoctamin 5 cause proximal LGMD2L and distal MMD3 muscular dystrophies. Am J Hum Genet 2010; 86: 213-221.

12 Krahn M, Beroud C, Labelle V et al: Analysis of the DYSF mutational spectrum in a large cohort of patients. Hum Mutat 2009; 30: E345-E375.

13 van der Kooi AJ, Frankhuizen WS, Barth PG et al: Limb-girdle muscular dystrophy in the Netherlands: gene defect identified in half the families. Neurology 2007; 68: 2125-2128.

14 Guglieri M, Magri F, D’Angelo MG et al: Clinical, molecular, and protein correlations in a large sample of genetically diagnosed Italian limb girdle muscular dystrophy patients. Hum Mutat 2008; 29: 258-266.

15 Rosales XQ, Gastier-Foster JM, Lewis S et al: Novel diagnostic features of dysferlinopathies. Muscle Nerve 2010; 42: 14-21.

16 Wenzel K, Carl M, Perrot A et al: Novel sequence variants in dysferlin-deficient muscular dystrophy leading to mRNA decay and possible C2-domain misfolding. Hum Mutat 2006; 27: 599-600. 
17 Shunchang S, Fan Q, Huacheng W et al: Dysferlin mutation in a Chinese pedigree with Miyoshi myopathy. Clin Neurol Neurosurg 2006; 108: 369-373.

18 Nguyen K, Bassez G, Bernard R et al: Dysferlin mutations in LGMD2B, Miyoshi myopathy, and atypical dysferlinopathies. Hum Mutat 2005; 26: 165.

19 Liewluck T, Pongpakdee S, Witoonpanich R et al: Novel DYSF mutations in Thai patients with distal myopathy. Clin Neurol Neurosurg 2009; 111: 613-618.

20 Santos R, Oliveira J, Vieira $\mathrm{E}$ et al: Private dysferlin exon skipping mutation (c.5492G $>$ A) with a founder effect reveals further alternative splicing involving exons 49-51. J Hum Genet 2010; 55: 546-549.

21 Leshinsky-Silver E, Argov Z, Rozenboim L et al: Dysferlinopathy in the Jews of the Caucasus: a frequent mutation in the dysferlin gene. Neuromuscul Disord 2007; 17: 950-954.

22 Ro LS, Lee-Chen GJ, Lin TC et al: Phenotypic features and genetic findings in 2 chinese families with Miyoshi distal myopathy. Arch Neurol 2004; 61: 1594-1599.

23 Fanin M, Nascimbeni AC, Aurino S et al: Frequency of LGMD gene mutations in Italian patients with distinct clinical phenotypes. Neurology 2009; 72: 1432-1435.

24 Takahashi T, Aoki M, Tateyama M et al: Dysferlin mutations in Japanese Miyoshi myopathy: relationship to phenotype. Neurology 2003; 60: 1799-1804.

25 Oh SH, Kang SW, Lee JG, Na SJ, Kim TS, Choi YC: Clinical and pathological characteristics of four Korean patients with limb-girdle muscular dystrophy type 2B. J Kor Med Sci 2004; 19: 447-452.

26 Fanin M, Nascimbeni AC, Angelini C: Muscle protein analysis in the detection of heterozygotes for recessive limb girdle muscular dystrophy type $2 \mathrm{~B}$ and $2 \mathrm{E}$. Neuromuscul Disord 2006; 16: 792-799.

27 O'Donovan MC, Oefner PJ, Roberts SC et al: Blind analysis of denaturing highperformance liquid chromatography as a tool for mutation detection. Genomics 1998; 52: 44-49.

28 Ho M, Gallardo E, McKenna-Yasek D et al: A novel, blood-based diagnostic assay for limb girdle muscular dystrophy 2B and Miyoshi myopathy. Ann Neurol 2002; 51: 129-133.

29 Nigro V, Okazaki Y, Belsito A et al: Identification of the Syrian hamster cardiomyopathy gene. Hum Mol Genet 1997; 6: 601-607.

30 den Dunnen JT, Antonarakis SE: Mutation nomenclature; in Haines JL et al (eds): Current Protocols in Human Genetics. New York: John Wiley and Sons, Inc., 2003, Chapter 7, Unit 713.

31 den Dunnen JT, Antonarakis SE: Nomenclature for the description of human sequence variations. Hum Genet 2001; 109: 121-124.

32 den Dunnen JT, Antonarakis SE: Mutation nomenclature extensions and suggestions to describe complex mutations: a discussion. Hum Mutat 2000; 15: 7-12.

33 Desmet FO, Hamroun D, Lalande M et al: Human Splicing Finder: an online bioinformatics tool to predict splicing signals. Nucl Acids Res 2009; 37: e67.
34 Xiao W, Oefner PJ: Denaturing high-performance liquid chromatography: a review. Hum Mutat 2001; 17: 439-474.

35 De Luna N, Freixas A, Gallano P et al: Dysferlin expression in monocytes: a source of mRNA for mutation analysis. Neuromuscul Disord 2007; 17: 69-76.

36 Pramono ZA, Tan CL, Seah IA et al: Identification and characterisation of human dysferlin transcript variants: implications for dysferlin mutational screening and isoforms. Hum Genet 2009; 125: 413-420.

37 Foxton RM, Laval SH, Bushby KM: Characterisation of the dysferlin skeletal muscle promoter. Eur J Hum Genet 2004; 12: 127-131.

38 Krahn M, Borges A, Navarro $\mathrm{C}$ et al: Identification of different genomic deletions and one duplication in the dysferlin gene using multiplex ligation-dependent probe amplification and genomic quantitative PCR. Genet Test Mol Biomarkers 2009; 13: $439-442$.

39 Urtizberea JA, Bassez G, Leturcq F et al: Dysferlinopathies. Neurol India 2008; 56: 289-297.

40 Torella A, Trimarco A, Blanco Fdel V et al: One hundred twenty-one dystrophin point mutations detected from stored DNA samples by combinatorial denaturing highperformance liquid chromatography. J Mol Diagn 2010; 12: 65-73.

41 Frischmeyer PA, van Hoof A, O'Donnell $K$ et al: An mRNA surveillance mechanism that eliminates transcripts lacking termination codons. Science (New York, NY) 2002; 295: 2258-2261.

42 Culbertson MR: RNA surveillance. Unforeseen consequences for gene expression, inherited genetic disorders and cancer. Trends Genet 1999; 15: 74-80.

43 van Hoof A, Parker R: Messenger RNA degradation: beginning at the end. Curr Biol 2002; 12: R285-R287.

44 Maquat LE: Molecular biology. Skiing toward nonstop mRNA decay. Science (New York, NY) 2002; 295: 2221-2222.

45 Wallefeld W, Krause S, Nowak KJ et al: Severe nemaline myopathy caused by mutations of the stop codon of the skeletal muscle alpha actin gene (ACTA1). Neuromuscul Disord 2006; 16: 541-547.

46 Angelini $C$, Nardetto L, Borsato $C$ et al: The clinical course of calpainopathy (LGMD2A) and dysferlinopathy (LGMD2B). Neurol Res 2010; 32: 41-46.

47 Nigro V: Molecular bases of autosomal recessive limb-girdle muscular dystrophies. Acta Myol 2003; 22: 35-42.

(c) This work is licensed under the Creative Commons Attribution-NonCommercial-Share Alike 3.0 Unported Licence. To view a copy of this licence, visit http://creativecommons. org/licenses/by-nc-sa/3.0/

Supplementary Information accompanies the paper on European Journal of Human Genetics website (http://www.nature.com/ejhg) 